\title{
Nonlinear effects of oil prices on inflation, growth, budget deficit, and unemployment
}

\author{
NGUYEN THI NGOC TRANG \\ University of Economics HCMC - trangtcdn@ueh.edu.vn \\ DINH THI THU HONG \\ University of Economics HCMC - hongtcdn@ueh.edu.vn
}

\begin{abstract}
ARTICLE INFO ABSTRACT
\end{abstract}
Article history:

Received:

Mar. 17, 2016

Received in revised form:

May 19, 2016

Accepted:

Dec. 31,2016

Keywords:

Oil price impact

TVAR model

Oil price threshold.
In oil-exporting countries such as members of the OPEC, fluctuations in oil prices exert a significant impact on the domestic economy. Currently, a sharp reduction in oil prices results in several adverse effects; however, for such a crude-oil exporter that is also an importer of petroleum products as Vietnam, does a rise or drop in oil prices is beneficial to its development? This paper attempts to determine the oil price threshold while analyzing oil price effects on several macro factors, such as inflation, GDP growth, budget deficit, and unemployment rate over the 2000-2015 period. Using TVAR model, we detect an oil price threshold of USD27.6/barrel. Moreover, an increase in the price of oil, which exceeds this threshold, will cause a rise in inflation, budget deficit, and unemployment rate. Still, there is no significant evidence of the impact of oil prices on GDP growth. 


\section{Introduction}

Similar to other kinds of materials, oil is one of the essential energy sources for manufacture and transport of goods. Oil prices, therefore, impact positively on production and consumer prices, and on the other hand their fluctuations should lead to temporary reduction in the total output as there is a pause in corporate investment under uncertain circumstances or due to rising costs in reallocation of resources.

Despite being one of the crude oil exporters, due to limited domestic supplies and reserves, Vietnam has imported large quantities of oil products annually to respond to domestic demand. Thus, the economy seems to be sensitive to oil price fluctuations, compared to others with larger oil supplies. Moreover, Vietnam's oil prices are affected greatly by price control and intervention policies as adopted by the Government.

Thus, the issue of response of an economy to oil price shocks receives rapt attention of both academia and policy makers. In fact, much research addresses the relation between oil prices and macro variables for the cases of the US and OECD countries, or a group of Asian countries (excluding Vietnam), while a few studies conducted in Vietnam inspect such macro factors as growth, inflation, public expenditure, or unemployment rate, albeit with inadequate examination of effects of oil price shocks on these factors.

To fill this gap we focus our investigation on these relations in contrast to other studies on the same topic, using TVAR estimation to explore the existence of any oil price threshold that alters the impact of oil price shocks on the economy, besides the impulse response analysis to examine oil price effects on these four macro variables.

\section{Theoretical foundation}

2.1. Oil price fluctuations and their impacts on the economy

- Oil price effects through total supplytotal demand relation

According to the Keynesian theory, high costs of production materials (oil prices) would give rise to production costs and consumer prices, reducing real wages and thereby the labor supply. This is conducive to a negative relation between oil prices and economic efficiency, yet a positive correlation between oil prices and other prices as well as unemployment rate. From the standpoint of oil demand and inputs in the production function including labor, capital, and energy, when oil prices rise, firms will have to decide between reduced degree of oil use and higher production costs, thus causing a reduction in output. In addition, rising crude oil prices result in almost instant increases in the prices of alternative fuel sources or oil products, causing firms to give consideration of whether they should make less oil use or accept rising costs and consequently causing a drop in the growth rate and productivity.

Hamilton (1983) initiated approaches to demonstrate that a rise in oil prices could negatively affect the macro efficiency. Bernanke (1983) argued that when firms are 
aware of increasing uncertainties about future oil prices, it is best to postpone their investment decisions, which leads to lower total output. Particularly, as firms have to face the choice of technology pertaining to energy efficiency, the more volatile the oil prices, the more important their decision to defer investments.

Supporting this viewpoint, Ferderer (1996) documented that the instability derived from oil price shocks causes a decline in investment demand, arguing for a negative correlation between oil prices and output but their positive association with inflation. Meanwhile, if consumers anticipate that an increase in energy prices is temporary, they may have to save less or borrow more, thereby causing a decrease in real balance and an increase in prices (Cologni \& Manera, 2008). Thus, one can see that rising oil prices are attributable to not only economic slowdown but also increased inflation.

Given goods supply, rising oil prices will reduce output as this signals that the availability of primary inputs for production will decline. As a consequence, the growth rate and productivity drop, and lower productivity growth reduces rates of increase in real wages and increases unemployment (Brown $\&$ Yucel, 1999, 2002). Thus, oil price shocks may increase the marginal cost of production in many fields, diminishing output and therefore causing higher unemployment rates. In addition, higher oil prices raising the costs of inputs are associated with reducing degrees of investment and affect volumes of output.

Another transmission channel of oil price shocks to economic activities is the wealth shift, caused by rising oil prices, from oil importers to oil exporters (Fried \& Schultze, 1975). Higher oil prices can be regarded as a kind of tax imposed by oil exporters on oilconsuming nations. Increases in income earned by the population in oil-exporting countries will boost consumer demand or demand for exports from oil-importing countries, which partly offsets the decline in their domestic demand.

According to the purchasing power parity (PPP) theory, increasing demand for manufactured goods from oil-importing countries will lead to adjustments to the exchange rate in order to keep constant the aggregate demand in these countries. Nevertheless, Brown and Yucel (2002) maintained that if prices are rigid, a reduction in demand for goods, especially energy-intensive goods, in the oil-importing countries, should be conducive to higher unemployment rates and reduced GDP growth rates. Previously, Mork (1994) also explained this transmission mechanism using real balance effect, whereby a rise in oil prices would increase demand for money. When there is no corresponding increase in money supply, higher interest rates will have an effect on the growth rate.

- Effects of oil prices through firms' and employees' responses

Some indirect effects of oil prices on inflation are behavioral responses of enterprises and employees. For non-energy goods and services offered by firms, increased production costs can be shifted into higher consumer prices, while employees may react to increases in the cost of living by requiring 
higher wages. In such a circumstance a decrease in real wage balance could produce negative effects on the wealthiness of the household and therefore on consumption and output (Cologni \& Manera, 2008).

Particularly, oil price shocks are likely to increase the marginal cost of production in many energy-intensive production sectors and lead firms to a switch to the application of new, less energy-intensive production modes. This change results in a reallocation of capital and labor between production areas, which may affect long-term unemployment. Since work skills features area-based specialization and it takes certain time to search for jobs, the absorption of labor would tend to lengthen. In other words, localized shocks will lead to increased unemployment rates due to the reallocation of labor resources. Loungani (1986) argued that if the oil price increase lingers, it can alter the structure of production and have a significant impact on unemployment.

- Effects of oil prices through monetary policy channel

A few other studies (Tatom, 1988; Bernanke et al., 1997) ascribed the monetary policy behavior to a channel for economic effects of oil price shocks. With the goals of enhancing employment opportunities and stabilizing prices, interest rate could be allowed to rise to curb inflation but could also be accompanied by unexpected drop-offs in demand. Additionally, if the response of prices is slow, then this policy could cause a large increase in the unemployment rate. On the other hand, to tackle a drop in aggregate demand and facilitate output stability, the central bank will adopt lower interest rates to temporarily offset losses in real GDP, which has a direct impact on prices, and inflation continues to rise. As a result, increased oil prices will affect the potential output in a complicated fashion. In addition, one can find that following an oil price shock, the energy-intensive parts of the economy would become obsolete and need to be replaced over time. To this extent inflation pressures could be even higher, so relatively more tightened monetary policy is necessary to bring inflation down to the target. Bernanke (2004) documented that responses of the central bank to inflationary pressures caused by rising oil prices should be reliant upon the overall conditions of the economy. If inflation levels remain low within the range allowed, it is not advisable to intervene by tightening monetary policy. Conversely, if recent oil price shocks do cause inflation to rise to the upper bound and the prices are forecast to keep on increasing, then it truly is.

Accordingly, most macroeconomic theories and recent studies suggested that increased oil prices have a negative influence on the economy, whether it is direct or indirect, through higher inflation or unemployment rates but lower growth rate. Moreover, depending on responses of monetary policy, increases in the price of oil can affect differently on growth. Empirical research was also developed to provide more evidence to substantiate these findings.

\subsection{Other relevant studies}

- Adverse effects of oil price shocks

One of the first investigations into the impact of increased oil prices on real income 
in the US and other developed nations is Hamilton (1983, 2011), who found a significant and negative correlation between oil price changes and real GNP growth of the US, and their positive correlation with unemployment rate. Most American economic recessions were suggested to be driven by sharp increases in the price of oil. Therefore, wide and unpredictable fluctuations of oil prices have enabled much research on their relations with macro variables such as real GDP, prices, unemployment, and real investment in different countries. Most of these studies, however, were conducted for the case of the US or obtained the sample of developed countries; only a few highlight the landscape of Asian countries, albeit excluding Vietnam. These studies have also shown undesirable effects of increases in oil prices on the macro variables although these may vary according to each specific period or country. Thus, the puzzle is whether reduction in oil prices exerts a positive impact on the economy, which stimulates a line of research to address the nonlinear impact of oil price shocks on the economy.

- Non-linear effects of oil price shocks

Increased oil prices are often accompanied by lower output, but reduced oil prices do not contribute to higher output. The reason for such asymmetric fact lies in reallocation effect and adjustment cost (Hamilton, 1996; Cunado \& Gracia, 2003; Huang et al., 2005). Rising oil prices lead to the shrinking of total supply as firms reduce their output to cope with higher input costs, and this is also conducive to lower aggregate demand because of the insecurity as can be felt by customers when they have to make investment decisions. Furthermore, increases in the oil of price result in the economic reallocation of energy, from the energy-sensitive sector to the energy-efficient one. All these factors combine to produce the effect on slowing down economic growth. On the other hand, lower oil prices stimulate production of firms and household spending, but a reallocation by sector in the opposite direction should stunt the growth. In addition, the rigidity of nominal wages (capital having been revised up after oil price increases) causes adjustment costs in the labor market, which means that nominal wages do not fall and production costs stay high. Hence, lower oil prices cannot be deemed a contributor to increased output.

Monetary policy has been suggested to be a cause of asymmetric effect (Bernanke et al., 1997), that is, the tightened or loosened policy can be adopted by the central bank to respond to effects of increased oil prices, whereas similar policy responses seem not to have been a case in the event of oil price reduction.

Other studies in favor of the asymmetric effect of oil prices (Hooker, 1996; Mork et al., 1994; Ferderer, 1996; Cunado \& Gracia, 2005) suggested that output does not respond symmetrically to oil price shocks because there are application and development of oil saving technologies or use of alternative resources during increased oil prices. In contrast, for a drop in the price of oil, firms immediately cease these types of investments to minimize sunk costs; hence, fewer effects are exerted on the economy when oil price decreases than when it increases. 
In the context of Vietnam some empirical investigations have been carried out to quantify oil price effects on macro factors (Nguyen et al., 2009; Narayan, 2010; Le \& Nguyen, 2011; Nguyen \& Tran, 2012; Pham et al., 2015), which, however, captures inflation and GDP growth rates without consideration of unemployment or budget expenditure. Furthermore, these authors have not defined the oil price threshold at which oil price changes exert favorable or adverse impact on the economy.

Thus, in order to address such a gap, this study aims to analyze the effects of the price of oil on macro variables, including inflation, growth, budget deficit, and inflation in Vietnam and also to find out the oil price threshold which governs the possible changes.

\section{Methodology}

\subsection{Research model}

We employ multivariate regression technique, using two-regime TVAR as follows:

$$
y_{t}=\left\{\begin{array}{l}
\propto_{1}+A_{1}(L) y_{t}+\varepsilon_{1 t} \text { if } q_{t} \leq \gamma \\
\propto_{2}+A_{2}(L) y_{t}+\varepsilon_{2 t} \text { if } q_{t}>\gamma
\end{array}\right.
$$

where vector of $y_{t}$ comprises inflation, budget deficit, growth and inflation rate.

$y_{t}=$ IOIL CPI DEFICIT GDP UNEMPLOYMENT]

where $q_{t}$ is a threshold variable (oil price), $\gamma$ denotes the threshold value, and $\alpha_{i}, i=1,2$, $\ldots$ is a $2 \times 1$ constant vector.

A lag polynomial features $A_{i}(L)=$ $A_{i 1} L+A_{i 2} L^{2}+\cdots+A_{i p} L^{p}$

where $A_{i j}$ is a $4 x 4 p$ matrix, $\mathrm{j}=1,2,3, \ldots$, and $\mathrm{L}$ is a lag operator.
Conditional impulse response function (CIRF) versus generalized impulse response function (GIRF)

After the TVAR estimation, the next step is to capture the impulse response function. Given the nonlinear model, the response of endogenous variables to a certain shock depends greatly on the past history, the state of the economy and the extent of the shock to be studied in period zero. The levels and signs of all the shocks have effects on economic performance during the surveyed period, or a shock at period $t$ may trigger a switch of regime at period $t+d$, where $d$ is the estimated lag of the threshold.

In this study we adopt both kinds of functions with mutual effects, including: (i) regime-dependent impulse response function (also known as conditional impulse response function-CIRF); and (ii) generalized impulse response function (GIRF). CIRF describes the response of the system to a shock in each regime identified through the inflation threshold that has been estimated. This implies that different responses can only be exhibited in an assumed regime, and CIRF, therefore, is considered the linear response function in the scope of a regime assumed.

Nevertheless, CIRF may not be compatible with the ultimate macro impact of a shock if a shift in regime throughout the cycle of reaction is likely enough, demanding consideration of the nonlinear impulse response analysis, which does not assume that the system remains in a certain regime at the start of the shock. For instance, a big enough shock for a variable results in a shift of the economy from the original regime. Generally, the nonlinear impulse response differs 
from its linear counterpart in that it depends on the history of time series, as well as the size or extent of the shock.

Accordingly, we perform analyses of both CIRF and GIRF, and the latter is estimated using bootstrapping as suggested by Balke (2000). Estimating GIRF is based on the reference of an impulse response function to conditional changes in expectations. The response at period $k$ (from 1 to $h$ ) of the variable $y$ to the shock at period $t\left(u_{t}\right)$ is defined by: (i) differences in the expected values of $y$ and the shock and particular historical condition $\left(\Omega_{t-1}\right)$ of the shock at period $t$ $\underline{1}$; and (ii) the expected value of $y$ in case of no existence of such a shock (Koop et al., 1996).

$$
\mathrm{GIRF}_{\mathrm{k}}=E\left(\mathrm{y}_{\mathrm{t}+\mathrm{k}} / \mathrm{u}_{\mathrm{t}} \Omega_{t-1}\right)-E\left(\mathrm{y}_{\mathrm{t}+\mathrm{k}} / \Omega_{t-1}\right)
$$

Following previous literature, we employ bootstrapping as a simulation technique to estimate the expected GIRF value. We consider the assumption that at the time of the shock the model is under a particular regime. In the first step initial values of actual and adjacent lag values of endogenous variables are selected corresponding to the historical value $\left(\Omega_{t-1}\right)$ for one of the defined regimes. The number of sets of initial conditions should be similar to that of observations in each regime where the impulse response function is estimated.

A series of shocks are next randomly selected from the remainder of the system. For each series, a number of variables concerned are simulated with the conditional model based on a particular history being considered. The model allows for regime changes during the simulation, which provides the estimate $E\left(y_{t+k} / \Omega_{t-1}\right)$. In the second step a similar random series of shocks are used, but in this case a superior shock $\left(u_{t}\right)$, equivalent to the shock of one standard deviation of the variable to be considered, is added at period $t$ to each series of shocks. This results in another estimate $E\left(\mathrm{y}_{\mathrm{t}+\mathrm{k}} / \mathrm{u}_{\mathrm{t}} \Omega_{t-1}\right)$. The difference between the results of the two estimations creates a simulated value of GIRF. This process is repeated 1,000 times for each set of initial observations. The average value of the simulated GIRF produces the final estimate of GIRF at period $k$ with a given regime. The confidence band of each period $k$ is then determined from the standard error of GIRF on the assumption that the shock follows a normal distribution. Afterward, this process is used to generate different impulse responses under other regimes.

\subsection{Data}

This study applies quarterly data covering the 2000-2015 period to several variables, such as oil price (OIL), inflation $(C P I)$, growth $(G D P)$, budget deficit (DEFICIT), and unemployment rate (UNEMPLOY$M E N T)$. The data are retrieved from ADB, Reuters, and GSO. Particularly, the oil price (in USD) is chosen as the spot price of crude oil on the Dubai market; inflation (\%) is calculated by rate of increase in the consumer price index (CPI); growth is measured by GDP growth rate; unemployment rate (\%) is obtained in the form of the unemployment rate recorded for urban areas; budget deficit (\%) is calculated as ratio of deficit to GDP. Data on oil prices and CPI are monthly data, so we take average to obtain quarterly data. Due to unavailability of quarterly statistics 
on budget deficit, Quadratic-match average is also performed. The sample covers $64 \mathrm{ob}-$ servations. The study uses original data series to estimate the parameters in TVAR as suggested by Pirovano (2012) for different types of VAR models ${ }^{1}$.

Descriptive statistics reveal sharp fluctuations in crude oil prices over the study pe- direction as the price of oil, the other three factors tend to fluctuate in opposite direction, which can be observed through the statistics on their correlation coefficients.

\section{Empirical results and discussion}

\section{Table 1}

Data description

\begin{tabular}{lccccc}
\hline & $\begin{array}{c}\text { Oil } \\
\text { price } \\
\text { (OIL) }\end{array}$ & CPI & GDP & $\begin{array}{c}\text { Budget deficit } \\
\text { (DEFICIT) }\end{array}$ & $\begin{array}{c}\text { Unemployment rate } \\
\text { (UNEMPLOYMENT) }\end{array}$ \\
\hline Mean & 63.39 & 7.22 & 6.71 & -0.60 & 4.71 \\
Median & 58.38 & 6.65 & 6.85 & -0.59 & 4.65 \\
Max & 116.67 & 27.75 & 9.26 & 0.33 & 6.51 \\
Min & 18.24 & -2.26 & 3.14 & -1.33 & 2.88 \\
Std. dev. & 32.18 & 6.59 & 1.26 & 0.52 & 1.09 \\
Obs. & 64 & 64 & 64 & 64 & 64 \\
\hline
\end{tabular}

Table 2

Correlation coefficients of variables

\begin{tabular}{lccccc}
\hline Correlation coef. & OIL & CPI & GDP & DEFICIT & $\begin{array}{c}\text { UNEMPLOY- } \\
\text { MENT }\end{array}$ \\
\hline OIL & 1.0000 & & & & \\
CPI & 0.5869 & 1.000 & & & \\
GDP & -0.4284 & -0.1558 & 1.000 & & \\
DEFICIT & -0.0528 & 0.5779 & 0.5281 & 1.000 & \\
UNEMPLOY- & -0.8252 & -0.3403 & 0.4222 & 0.2703 & 1.000 \\
MENT & & & & &
\end{tabular}

riod with their lowest and highest rates of USD18.24/barrel and USD116.67/barrel in Q4/2011 and Q2/2008 respectively. While the CPI of Vietnam fluctuates in the same

\subsection{Testing for nonlinearity}

Initially, we conduct a nonlinearity test for TVAR against the linear VAR model, using oil price as a threshold variable. The 
threshold value is a turning point at which oil price effects on macro variables vary from being significant to being insignificant, or vice versa. To check the null hypothesis of linearity $(\mathrm{m}=1$ regime) against nonlinearity ( $m=2$ regimes), we adopt the modified multivariate linearity test suggested by Hansen (1999) and Lo and Zivot (2001). The Likelihood Ratio statistic $L R$ is as follows:

$$
\begin{aligned}
& L R_{01}=T\left(\ln \left(\operatorname{det} \sum_{0}^{\wedge}\right)\right. \\
&\left.-\ln \left(\operatorname{det} \sum_{1}^{\wedge}\right)\right)
\end{aligned}
$$

where $\sum_{0}^{\wedge}$ denotes the covariance matrix estimated in the model under the null hypothesis and $\sum_{1}^{\wedge}$ is the matrix estimated using other alternatives. The nonlinearity test results are reported in Table 3.

\section{Table 3}

LR test results

LR test for nonlinearity against linearity

\begin{tabular}{lc}
\hline LR statistic & 185.4157 \\
p-value & 0.0000 \\
Estimated threshold & 27.6 \\
\hline
\end{tabular}

In Table 3 p-value $=0$ implies that the null hypothesis can be rejected and that the two-regime TVAR model, with the estimated oil price threshold of USD27.6/barrel is suitable to measure oil price effects on the Vietnam's economy. The optimal lag selected for TVAR as per AIC is 1.

\section{Table 4}

Results of lag length selection

\begin{tabular}{cc}
\hline $\begin{array}{c}\text { Number of } \\
\text { lags }\end{array}$ & $\begin{array}{c}\text { AIC for TVAR with } 1 \\
\text { threshold }\end{array}$ \\
\hline 1 & 17.00333
\end{tabular}
2
17.32921
3
19.38449
4
18.10672

Table 5 depicts the estimated results of TVAR with the oil price employed as a threshold variable. Oil price effects on macro variables are insignificant for the first regime, but significant mostly for the second one. Additionally, observations on oil prices above the threshold level (USD27.6/barrel) account for a large proportion (76.19\%); hence, we focus on the second regime to analyze the response of the economy to oil price shocks.

Oil price effects can be interpreted as follows: (i) below the threshold level of USD27.6/barrel no substantial evidence is found of their impacts on inflation, growth, budget deficit, and unemployment rate; and (ii) above this level a positive shock caused by increased oil prices gives rise to inflation, budget deficit, and unemployment rate, represented by their correlation coefficients at $1 \%, 10 \%$, and $5 \%$ levels respectively in the later term, whereas an insignificant effect is found on GDP.

The results of positive effects of oil price shocks on inflation and unemployment are in agreement with the findings of Hamilton (1983), Pindyck and Rotemberg (1983), Gisser and Goodwin (1986), Ferderer 


\section{Table 5}

TVAR estimation results using the price of oil as a threshold variable

\begin{tabular}{|c|c|c|c|c|c|c|}
\hline & \multicolumn{3}{|c|}{$\begin{array}{c}\text { Regime } 1 \\
\text { OIL }(-1)<=27.6\end{array}$} & \multicolumn{3}{|c|}{$\begin{array}{c}\text { Regime } 2 \\
\text { OIL }(-1)>27.6\end{array}$} \\
\hline \multirow[t]{2}{*}{$\%$ of obs. } & & $23.81 \%$ & & & $6.19 \%$ & \\
\hline & $\begin{array}{l}\text { Regr. } \\
\text { coef. }\end{array}$ & t-value & p-value & Regr. coef. & t-value & p-value \\
\hline (const.) & -0.8051 & -0.0371 & 0.9712 & -13.9612 & -2.0068 & 0.0512 \\
\hline OIL (-1) & -0.2142 & -1.6509 & 0.1332 & 0.1089 & 4.3624 & 0.0001 \\
\hline CPI (-1) & 0.3859 & 1.4489 & 0.1813 & 0.5735 & 5.2865 & 0.0000 \\
\hline GDP (-1) & 0.4321 & 0.7368 & 0.4800 & 0.4374 & 1.0454 & 0.3018 \\
\hline DEFICIT (-1) & 7.1623 & 1.3693 & 0.2041 & 2.7107 & 1.8095 & 0.0775 \\
\hline UNEMPLOYMENT (-1) & 1.5864 & 0.4345 & 0.6741 & 1.8834 & 2.0936 & 0.0424 \\
\hline AIC & 17.0033 & & & & & \\
\hline SIC & 19.5889 & & & & & \\
\hline SSR & 681.4938 & & & & & \\
\hline
\end{tabular}

(1996), Brown and Yucel (2002), Tang et al. (2010), Cunado and Gracia (2005), Cologni and Manera (2008), Bernanke et al. (1997), and Ran and Voon (2012). This is because an increase in the price of oil has led to rising production costs and consumer prices yet declining investment demand.

Oil price effect on GDP growth: This study finds neither significant impact of the oil price shock on growth in GDP or output in Vietnam, which is similar to Olomola and Adejumo (2006), nor its more persistent effect than those of prices and currency on output and investment (Tang et al., 2010). As also documented by Hamilton (1983) and Burbidge and Harrison (1984), changes in oil prices exert profound and negative influence on growth, but no evidence was produced for all observed terms. Thus, our finding on the oil price effect on growth is dissimilar to earlier studies in the context of $\mathrm{Vi}$ etnam as can be explained by oil price effects on output through different responses of monetary policy.

Oil price effect on budget deficit: The results are consistent with those of Rafiq et al. (2009) for the case of Thailand, which suggested that during the Asian financial crisis, the impact of oil price volatility are transmitted to the deficit. The effect, despite scarcely verified owing to limited empirical evidence as shown in previous investigations, well matches the characteristics of the Vietnam's 
economy during the study period due to several of the following reasons:

Increased oil prices raises production costs, reduces firms' earnings or tax revenues, and contributes to higher levels of budget deficit.

Higher oil prices, in spite of being favorable to oil exploiters and oil trading enterprises, inevitably have adverse influence on certain fields, such as transportation, production of fertilizers/plastics, exploitation of natural resources, fisheries, metallurgy, and most of the others. Along with exchange rate fluctuations, the price of crude oil affects greatly the cost of production and profitability of enterprises in the economy-the source of budget revenue. Firms whose materials for production are derived from crude oil would suffer a severe reduction in profit, which contributes indirectly to larger deficit.

Budget revenue from crude oil tends to shrink over the years.

In fact, budget revenue from crude oil sales, especially the proportion of crude oil revenue to total revenue tends to decline (i.e. increased oil prices do not contribute as greatly to budget revenue as before). Even during the year 2008 when increased oil prices reach the highest level, contributing crude oil revenue of VND89.6 thousand bil. (increase of $16.4 \%$, compared to that of 2007-VND76.98 thousand bil.), the proportion of crude oil revenue to total budget revenue decreases from $24.37 \%$ (2007) to $20.81 \%$ (2008) and significantly falls afterward. In 2015 the proportion amounts to approximately $7.1 \%$ (attributed to reduced

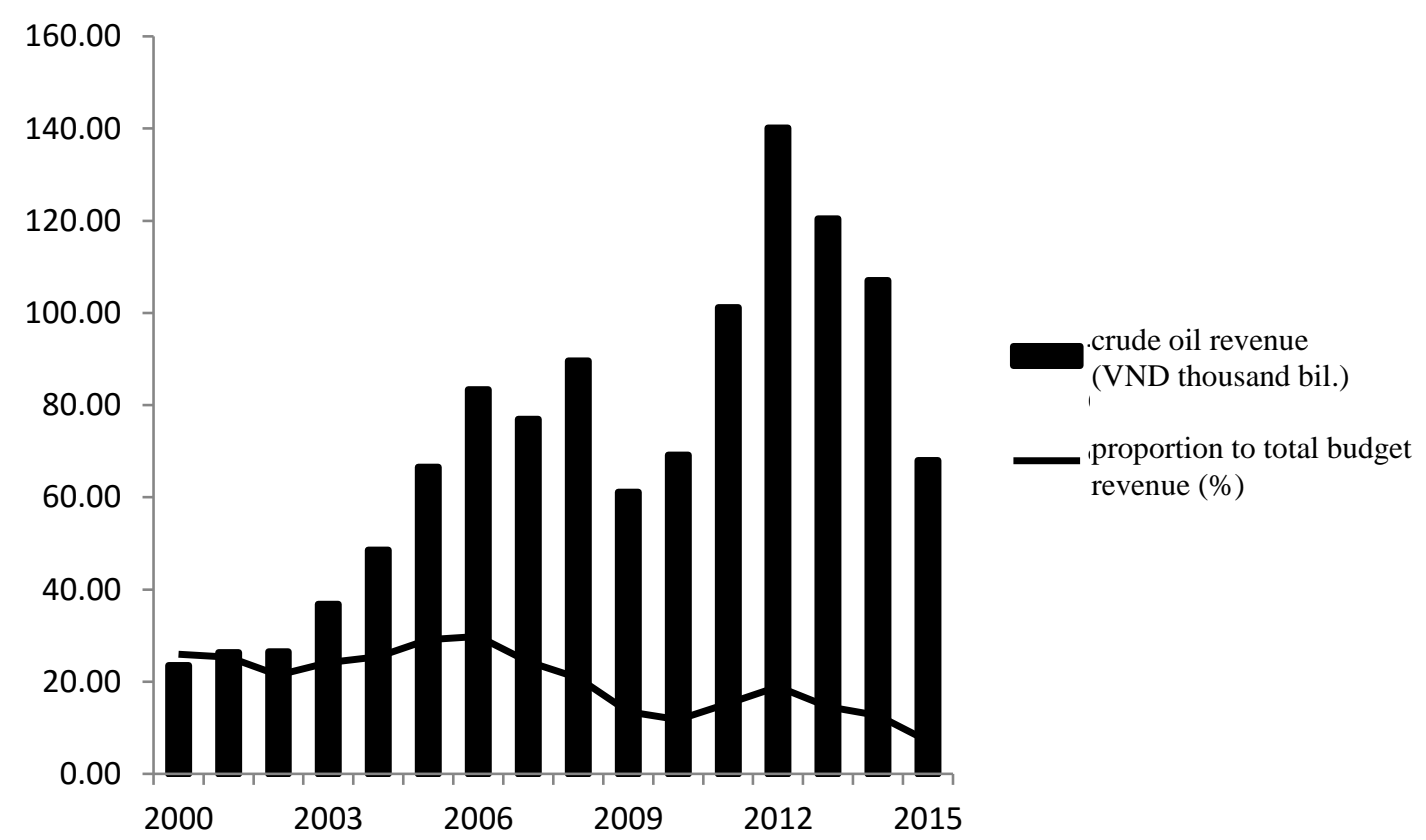

Figure 1. Contribution of crude oil sales to state budget

Source: GSO, MoF 
crude oil prices), and as of 2016 it is predicted to stay at $5.37 \%$ in the event the average crude oil price remains of USD60.00/barrel ${ }^{2}$.

In the meantime, demand for imported petroleum products is constantly on the increase to cater for manufacturing, services, and consumer sectors. increase spending for daily travel, thus forcing them to cut down consumption of other goods or reduce savings. Increased freight rates are associated with rising prices of consumer goods; thus, consumers would suffer concurrent disadvantages derived from the energy expenditure. This should contribute to limited consumption and curtailed production, causing economic stagnation and

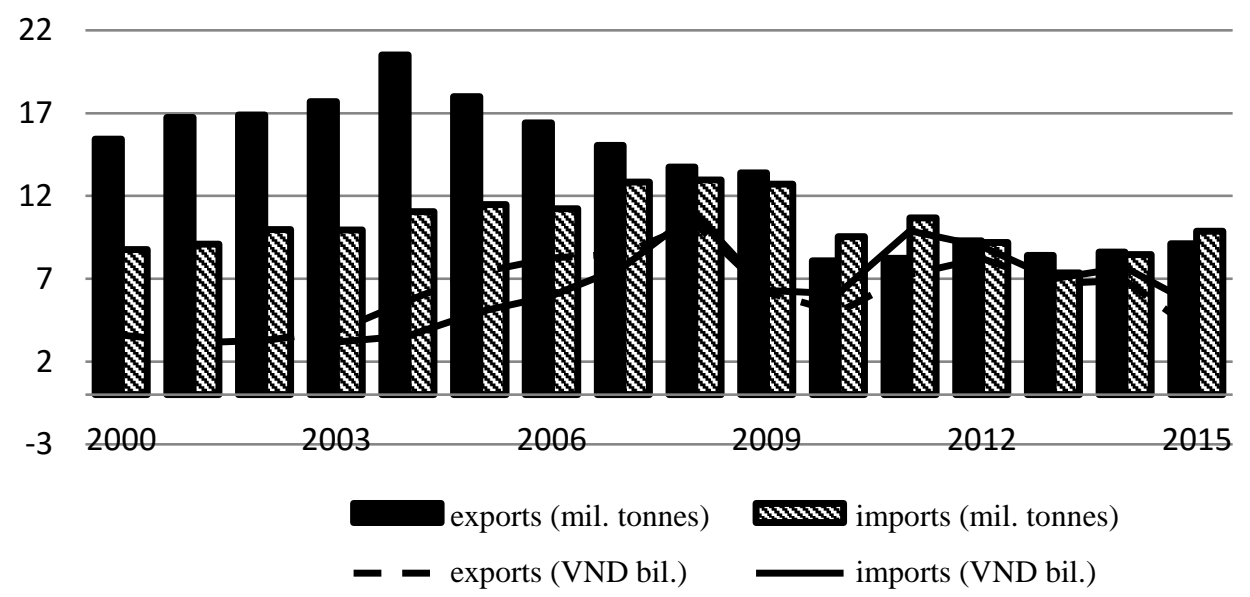

Figure 2. Crude oil exports compared to petroleum/oil imports

Source: GSO and Vietnam Petroleum Association (VINPA)

Accordingly, higher oil prices result in increased production costs yet lower firms' profitability, thereby causing reduced budget revenue or larger budget deficit.

In addition, there exist other indirect impacts such as rising oil prices attributable to increased inflation; monetary policy can be adjusted toward being more tightened in response to this by raising interest rates, which in turn lift further costs or reduce firms' investment, adversely affecting total state revenue $^{3}$. From the perspective of consumers, as the price of oil rises, households have to little increase in the budget revenue from consumer goods.

\section{Impulse response analysis}

As discussed in the Methodology Section, we perform a test on CIRF for each regime given a positive shock. 

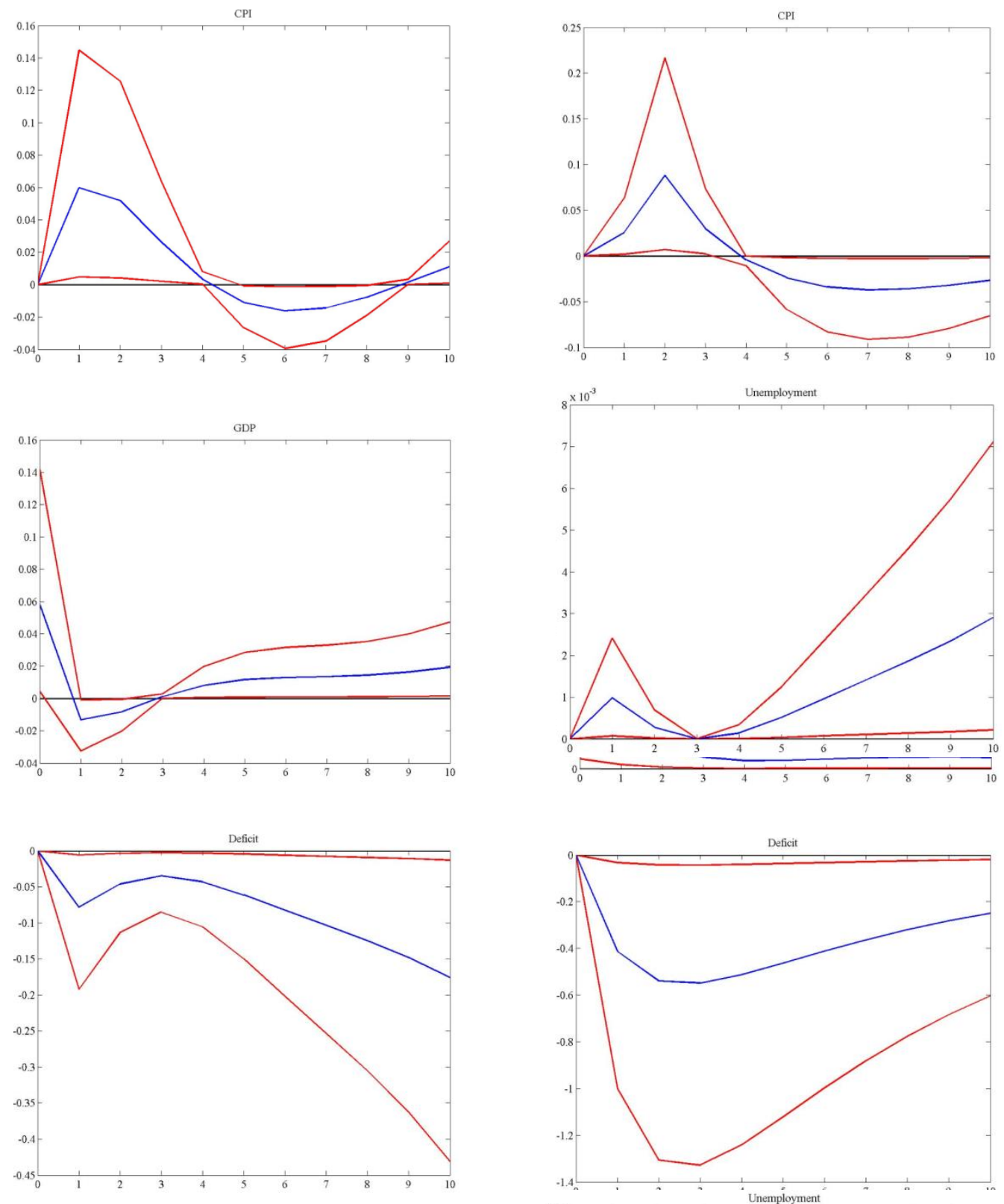

Figure 3. Conditional Impulse Response Function (CIRF)

Note: responses of CPI, GDP, DEFICIT, and UNEMPLOYMENT to the positive shock of OIL, corresponding to the first and second regimes

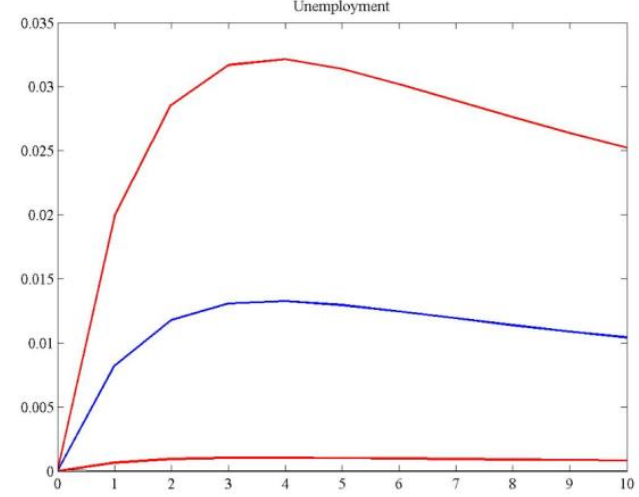


The results of impulse response analysis reveal that in Regime 1 with a shock of oil price increase of one standard deviation, inflation increases by $0.9 \%$ during the next two quarters and then reduces significantly to equilibrium after four quarters. On the other hand, regarding Regime 2 an oil price increase of one standard deviation causes inflation to increase by $0.06 \%$ in over one coming quarter and then decreases to the equilibrium rate after four quarters. After reaching the equilibrium the inflation rate tends to drop during later terms.

Concerning the response of GDP growth to the oil price shock, in Regime 1 when the oil price increases by one standard deviation, GDP reduces sharply by around $0.05 \%$ in less than one next quarter to below the equilibrium rate and steadily rises afterward. Meanwhile, in Regime 2, the response of GDP to the oil price shock is quite different from that in Regime 1: it declines gradually by $0.14 \%$ and becomes stable after three quarters.

As for budget deficit, in Regime 1 one standard deviation increase in the oil price shock entails increase in the deficit of $0.08 \%$ after one quarter; it then reduces slightly and continues rising after four quarters. The deficit response, nevertheless, is not similar in the second regime: it constantly increases up to the third quarter and decreases throughout the next ones.

In the same vein responses of unemployment to oil price shocks are differentiated for the two regimes. In Regime 1, an oil price shock leads to increase in unemployment of $0.0025 \%$ after one quarter. After that, it declines and returns to equilibrium in the third quarter but then steeply rises. Given Regime 2 , the unemployment rate increases sharply by approximately $0.008 \%$ right in the first quarter and continues to mount up in the next two ones; not until the fourth one does it slightly reduce despite remaining high.

Finally, to inspect the possibility of a shift from one regime to the other if the shock is strong enough, we employ another response function-GIRF. The results indicate differences as recorded from responses of GDP, budget deficit, and unemployment rate in Regime 1, whereas the CPI response, in respect of both regimes, appears not to diverge from itself when CIRF is considered. The evidence, once again, verifies vivid oil price effects on CPI as well as no particular shift from one regime to the other during oil price changes. Similar results are obtained concerning the other variables (plots of GIRF are not reported due to space constraint).

\section{Conclusion and policy implications}

\subsection{Conclusion}

The empirical findings from this study demonstrate the nonlinearity of oil price effects on the Vietnam's economy through such indicators as inflation, growth, budget deficit, and unemployment rate over the 2000-2015 period given both inspected regimes. The oil price threshold, as shown, is USD27.6/barrel.

In Regime 1, we find no evidence of significant effects of the price of oil on all the four macro variables. However, when oil prices exceed the threshold level of USD27.6/barrel in Regime 2, a shock of oil 
price increase has powerful impacts, which result in rising inflation, deficit, and unemployment rate. The GDP response, particularly, is not statistically significant in Regime 2. These results are in line with relevant theoretical and empirical findings as well as the reality of the Vietnam's economy in connection with the world' crude oil prices.

\subsection{Implications}

In terms of oil prices below the threshold (USD27.6/barrel), no significant evidence is revealed of higher oil prices which affect inflation, growth, budget deficit, and unemployment rate. Still, due to the data series demonstrating mostly their increase besides little reduction over the study period, it is imperative to have further research with more conclusive evidence.

Considering higher oil prices, their adverse effects on a certain economy are recognizable. In long terms this negative side can become a driving force for businesses, inspire management to adopt policies that encourage firms' technological investment toward economical and efficient use of energy sources, minimizing the need for oil usage. Also from the subjective perspective, the impact should be taken as a motivation for State's and firms' investments in the development of alternative fuel sources and increased use of them in production and daily life.

Additionally, the empirical results suggest certain risks posed to the economy at high oil prices, which demands price-related prevention measures, as particularly taken by oil importers or oil-based input users. Regarding managerial agencies, this is to motivate their continued development of derivatives market, satisfying the requirement for risk prevention.

A declining share of budget revenue from oil sales, the constantly reduced price of oil since the end of 2014, and the empirical results which show that rising oil prices will not help improve the deficit raise an issue that the State revenue should be specifically generated from domestic services and manufacturing to ensure stability and sustainability. Moreover, this should lead to further issuance of policies on regulating oil prices or those pertaining to corporate investment and trading. Favorable conditions and support should, therefore, be provided to improve firms' competitiveness and earnings, as a means to cultivate more revenue

\section{Notes}

1 Pirovano (2012)

2 according to the 2016 budget plan approved by the Government

3 This transmission channel is clarified in Bohi (1991) and Bernanke et al. (1997).

\section{References}

Balke, N. S. (2000). Credit and economic activity: Credit regimes and nonlinear propagation of shocks. Review of Economics and Statistics, 82(2), 344-349.

Bernanke, B. (1983). Irreversibility, uncertainty, and cyclical investment. Quarterly Journal of Economics, 98(1), 85-106.

Bernanke, B. (2004). Oil and the economy. Remarks at the Distinguished Series, Darton College, Albany, Georgia, 10/2014. 
Bernanke, B., Gertler, M., \& Watson, M. (1997). Systematic monetary policy and the effects of oil shocks. Brookings Papers on Economic Activity, 28(1), 91-157.

Bohi, D. R. (1991). On the macroeconomic effects of energy price shocks. Resources and Energy, 13, 145-162.

Brown, S. P. A., \& Yucel, M. K. (1999). Oil prices and U.S. aggregate economic activity: A question of neutrality. Federal Reserve Bank of Dallas Economic and Financial Review, (Second Quarter), 16-23.

Brown, S. P. A., \& Yucel, M. K. (2002). Energy prices and aggregate economic activity: An interpretative survey. Quarterly Review of Economics and Finance, 42(2), 193-208.

Burbidge, J., \& Harrison, A. (1984). Testing for the effects of oil-price rise using vector autoregressions. International Economic Review, 25(2), 459-484.

Cologni, A., \& Manera, M. (2008). Oil prices, inflation and interest rates in a structural cointegrated VAR model for the G-7 countries. Energy Economics, 30(3), 856-888.

Cunado, J., \& Perez de Gracia, F. (2003). Do oil price shocks matter? Evidence for some European countries. Energy Economics, 25(2), 137-154.

Cunado, J., \& Perez de Gracia, F. (2005). Oil prices, economic activity and inflation: Evidence for some Asian countries. Quarterly Review of Economics and Finance, 45(1), 65-83.

Ferderer, J. P. (1996). Oil price volatility and the macroeconomy. Journal of Macroeconomics, 18(1), 1-26.

Fried, E. R., \& Schultze, C. L. (1975). Higher oil prices and the world economy. Washington, DC: The Brookings Institution.

Gisser, M., \& Goodwin, T. (1986). Crude oil and the macroeconomy: Tests of some popular notions. Journal of Money Credit Banking, 18(1), 95-103.

Hamilton, J. D. (1983). Oil and the macroeconomy since World War II. Journal of Political Economy, 92(2), 228-248.

Hamilton, J. D. (1996). This is what happened to the oil price-macroeconomy relationship. Journal of Monetary Economics, 38(2), 215220.

Hamilton, J. D. (2011). Nonlinearities and the macroeconomic effects of oil prices. Macroeconomic Dynamics, 15(S3), 364-378.

Hooker, M. A. (1996). What happened to the oil price-macroeconomy relationship? Journal of Monetary Economics, 38(2), 195-213.

Huang, B.-N., Hwang, M. J., \& Hsiao, P.-P. (2005). The asymmetry of the impact of oil price shocks on economic activities: An application of the multivariate threshold model. Energy Economics, 27(3), 455-476.

Koop, G., Pesaran, M. H., \& Potter, S. (1996). Impulse response analysis in nonlinear multivariate models. Journal of Econometrics, 74(1), 119-148.

Le, V. T., \& Nguyen, T. T. V. (2011). The impact of oil prices, real effective exchange rate and inflation on economic activity: Novel evidence for Vietnam. Discussion paper series, Kobe University, 3/2011.

Loungani, P. (1986). Oil price shocks and the dispersion hypothesis. Review of Economics and Statistics, 58, 536-539.

Mork, K. A. (1994). Business cycles and the oil market. The Energy Journal, (Special Issue), $15-38$.

Mork, K. A., Olsen, O., \& Mysen, H. T. (1994). Macroeconomic responses to oil price increases and decreases in seven OECD countries. The Energy Journal, 15(4), 19-36. 
Narayan, P. K., \& Narayan, S. (2010). Modelling the impact of oil prices on Vietnam's stock prices. Applied Energy, 87(1), 356-361.

Nguyen, D. T., Bui, T., \& Dao, N. T. (2009). Effects of increased petroleum and oil prices: Some preliminary quantitative analyses (in Vietnamese). VNU Journal of Science: Economics and Business, 25, 25-38.

Nguyen, T. L. H., \& Tran, T. G. (2012). Effects of oil price shocks on the Vietnam's economy and forecasts for the 2012-2020 period (in Vietnamese). Institutional Research Project 2011-2012. Vietnam: University of Economics Ho Chi Minh City.

Olomola, P. A., \& Adejumo, A.V. (2006). Oil price shock and macroeconomic activities in Nigeria. International Research Journal of Finance and Economics, 3, 28-34.

Pham, T. H. A., Chu, K. L., Dao, B. N., Nguyen, M. P., \& Tran, H. T. (2015). Oil price fluctuations and their effects on the Vietnam's economy (in Vietnamese). Research report 2/2015. Vietnam: Banking Academy.
Pindyck, R. S., \& Rotemberg, J. J. (1983). Dynamic factor demands and the effects of energy price shocks. American Economic Review, 73(5), 1066-1079.

Pirovano, M. (2012). Monetary policy and stock prices in small open economies: Empirical evidence for the new EU member states. Economic Systems, 36(3), 372-390.

Rafiq, S., Salim, R., \& Bloch, H. (2009). Impact of crude oil price volatility on economic activities: An empirical investigation in the Thai economy. Resources Policy, 34, 121132.

Ran, J., \& Voon, J. P. (2012). Does oil price shock affect small open economies? Evidence from Hong Kong, Singapore, South Korea and Taiwan. Applied Economic Letters, 19, 1599-1602.

Tang, W., Wu, L., \& Zhang, Z. (2010). Oil price shocks and their short- and long-term effects on the Chinese economy. Energy Economics, 32(1), S3-S14.

Tatom, J. (1988). Are the macroeconomic effects of oil price changes symmetric? Carnegie-Rochester Conference Series on Public Policy, 28(1), 325-368. 